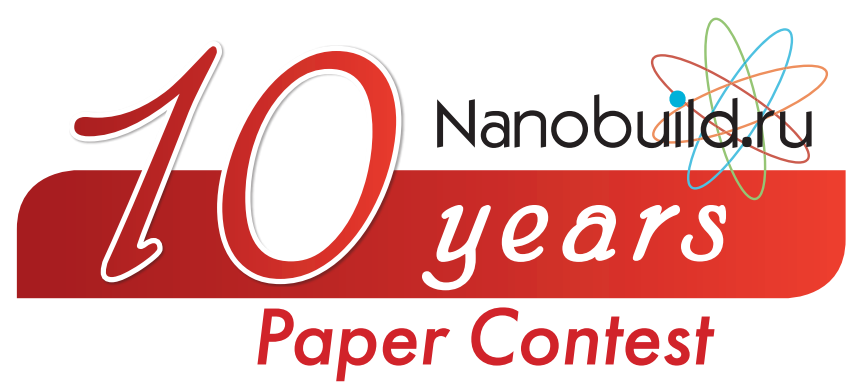

UDC 621.186.2

Author: BAIKOV Igor Ravilevich, Doctor of Engineering, Professor, Full member of Academy of Mining Engineering, Head of Department «Industrial Heat Powering», Ufa State Petroleum Technological University; Kosmonavtov St., 1, Ufa, Bashkortostan Republic, Russia, 450064, pte.ugntu@rusoil.net;

Author: SMORODOVA Olga Viktorovna, PhD in Engineering, Associate Professor of Department «Industrial Heat Powering», Ufa State Petroleum Technological University; Kosmonavtov St., 1, Ufa, Bashkortostan Republic, Russia, 450064, olga_smorodova@mail.ru;

Author: KITAEV Sergey Vladimirovich, Doctor of Engineering, Full member of International Academy of Engineering, Professor of Department «Transport and Storage of Oil and Gas», Associate Professor, Ufa State Petroleum Technological University; Kosmonavtov St., 1, Ufa, Bashkortostan Republic, Russia, 450064, svkitaev@mail.ru

\title{
NANOCOMPOSITE PIPELINES ENERGY EFFICIENCY
}

\section{Extended Abstract:}

Today multilayer metal-plastic pipes manufactured by means of special technologies are becoming widely applied. The main advantages of the so-called nanocomposite pipes are the increased service life (up to 80-100 years) and high corrosion resistance.

The paper considers energy aspect of application of nanocomposite pipes in utility systems. It was shown that due to the low roughness, even at the initial stage of operation, electric power consumption for driving pumps in nanocomposite systems is almost 1,5 times lower respect to steel pipelines. In the long term, due to the buildup of deposits in steel pipelines, the effect increases by an average of $8 \%$ for each subsequent year of operation.

Key words: nanotechnology, composite pipes, roughness, pressure loss, energy efficiency. 
MACHINE-READABLE INFORMATION ON CC-LICENSES (HTML-CODE) IN METADATA OF THE PAPER

$<$ a rel="license" href="http://creativecommons.org/licenses/by/4.0/" $><$ img alt="Creative Commons License" style="borderwidth:0" src="https://i.creativecommons.org/1/by/4.0/88x31.png" $/></ \mathrm{a}><$ br $/><$ span xmlns:dct="http://purl.org/dc/ terms $/ "$ property $="$ dct:title" $>$ Nanocomposite pipelines energy efficiency $</$ span $>$ by $<$ a xmlns:cc $="$ http: $/ /$ creativecommons. org/ns\#" href="Nanotehnologii v stroitel'stve = Nanotechnologies in Construction. 2018, Vol. 10, no. 3, pp. 20-36. DOI: dx.doi.org/10.15828/2075-8545-2018-10-3-20-36" property="cc:attributionName" rel="cc:attributionURL">Baikov I.R., Smorodova O.V., Kitaev S.V. $</ a>$ is licensed under a $<$ a rel="license" href="http://creativecommons.org/licenses/ by/4.0/">Creative Commons Attribution 4.0 International License $</ \mathrm{a}>$. $<$ br $/>$ Based on a work at $<$ a xmlns:det="http:// purl.org/dc/terms/" href="http://nanobuild.ru/en_EN/nanobuild-3-2018/" rel="dct:source">http://nanobuild.ru/ en_EN/nanobuild-3-2018/</a $>$. $<$ br $/>$ Permissions beyond the scope of this license may be available at $<$ a xmlns:cc="http: $/ /$ creativecommons.org/ns\#" href="pte.ugntu@rusoil.net" rel="cc:morePermissions">pte.ugntu@rusoil.net</a>.

\section{References:}

1. Potsius A.V. Klei, adgeziya, tekhnologiya skleivaniya. [Adhesives, adhesion, gluing technology]. S-Peterburg: «Professiya» [St. Petersburg: «Profession»]. 2007. 172 p. (In Russian).

2. Motuhari G., Tabankia F. Thermoplastische ersetzen Stahl und Aluminium. Kunststoffe. 1999. No. 3. P. 74-76.

3. Gaube E., Diedrich G. Kunststoffe im Rohrleitungs- und Apparatebau. Chemie Ingenieur Technik. 1978. Vol. 50. No. 3. P. 155-166. [auf Deutsch].

4. Meier K. Kunststoff-Rohre für Chemie-Anlagen. Kunststoff-Rundschau. 1973. No. 6. P. 273-278.

5. Karimov E.Kh., Karimov O.Kh., Movsumzade E.M., Boev E.V. The influence of metal nanoparticles on the mechanical properties of composite materials. Nanotehnologii v stroitel'stve $=$ Nanotechnologies in Construction. 2017, Vol. 9, no. 4, pp. 22-47. DOI: dx.doi.org/10.15828/2075-8545-2017-9-4-22-47. (In Russian).

6. Prodromou A.G., Lomov S.V., Verpoest I. The method of cells and the mechanical properties of textile composites. Composite Structures. 2011. Vol. 93. No. 4. Pp. 12901299.

7. Vallons K., Adolphs G., Lucas P., Lomov S.V., Verpoest I. The influence of the stitching pattern on the internal geometry, quasi-static and fatigue mechanical properties of glass fibre non-crimp fabric composites. Composites Part A: Applied Science and Manufacturing. 2014. Vol. 56. P. 272-279.

8. Ovchinnikov N.L., Arbuznikov V.V., Kapinos A.P., Belozerov A.G., Butman M.F. Vliyaniye mekhanoaktivatsii montmorillonita na effektivnost' interkalyatsii poligidroksokompleksov alyuminiya pri formirovanii sloisto-stolbchatoy struktury [Influence of mechanoactivation of montmorillonite on the efficiency of intercalation of aluminum polyhydroxo complexes in the formation of stratified-columnar structure]. Rossiiskie nanotekhnologii [Russian Nanotechnologies]. 2015. Vol. 10. no. 3-4. P.74-79. (In Russian). 
9. Butman M.F., Belozerov A.G., Karasev N.S., Kochkina N.Ye., Khodov I.A., Ovchinnikov N.L. Strukturnyye i teksturnyye svoystva pillarnogo montmorillonita pri interkalyatsii krupnorazmernykh Al- i Al/Ce-poligidroksokompleksov [Structural and Textural Properties of Pillar Montmorillonite in the Intercalation of Large-Size Aland $\mathrm{Al} / \mathrm{Ce}-\mathrm{Polyhydroxo}$ Complexes]. Rossiiskie nanotekhnologii [Russian Nanotechnologies]. 2015. Vol. 10. no. 9-10. P. 36-41. (In Russian).

10. Kudryavtsev P.G., Figovsky O.L. Heat-resistant inorganic binders. Nanotehnologii v stroitel'stve $=$ Nanotechnologies in Construction. 2017, Vol. 9, no. 2, pp. 66-81. DOI: dx.doi.org/10.15828/2075-8545-2017-9-2-66-81. (In Russian).

11. Ben Gardi R., Roth J.R. et al. Sterilization and plasma processing of room temperature surfaces with a one atmosphere uniform glow discharge plasma (OAUGDP) Surface Coatings Technology. 2000. P.131.

12. Carr A.K. Increase in the surface energy of metal and polymeric surfaces using the one atmosphere uniform glow discharge plasma MS in EE Thesis University of Tennesse. 1997.

13. Samoylovich V.G., Gibalov V.I., Kozlov K.V. Fizicheskaya khimiya bar'yernogo razryada [Physical chemistry of barrier discharg]. Moscow: Izdatel'stvo MGU [Moscow: MSU Publishing House]. 1989. 176 p. Available at: http://www.studmed.ru/samoylovich-vg-gibalov-vi-kozlov-kv-fizicheskaya-himiya-barernogo-razryada_6154bef13ee. html\#. (Accessed: 03.04.2018).

14. Kalmykov A.V., Kosnikov G.A., Bespalov E.N., Petrovich S.Yu. Kompozity - alyuminiyevaya matritsa - tyazhelyye dispersnyye chastitsy [Composites - aluminum matrix heavy dispersed particles] // Kompozity i nanostruktury [Composites and nanostructures]. 2017. Vol. 9. No. 3-4 (35-36). P. 165-166. Available at: http://www.issp. ac.ru/journal/composites/2017/ Kalmykov-3-4-2017.pdf. (Accessed: 03.04.2018).

15. Harris B. Fatigue in composits. England: Woodheard Publish Lmt. 2003. 742 p. [In English].

16. Owen $M$. J., Dukes $R$. Failure of glass-reinforced plastics under single and repeated loading. Journal of Strain Analysis for engineering design. 1967. Vol. 2. No. 4. P. 272-279.

17. Federal'nyy zakon «Ob energosberezhenii i o povyshenii energeticheskoy effektivnosti i o vnesenii izmeneniy v otdel'nyye zakonodatel'nyye akty Rossiyskoy Federatsii» 23.11.2009 N 261-FZ (poslednyaya redaktsiya) [Federal Law «On Energy Saving and Improving Energy Efficiency and Amending Certain Legislative Acts of the Russian Federation» 23.11.2009 №261-FZ (last edition)]. [in Russian]. Available at: http:// legalacts.ru/doc/FZ-ob-jenergosberezhenii-i-o-povyshenii-jenergeticheskoj-jeffektivnosti-i-o-vnesenii-izmenenij-v-otdelnye-zakonodatelnye-akty-Rossijskoj-Federacii/. (Accessed: 03.04.2018).

18. Energeticheskaya strategiya Rossii na period do 2030 goda. Utverzhdena rasporyazheniyem pravitel'stva RF №1715-r 13.11.2009 (aktualizirovannaya versiya ot 01.01.2018). [Energy strategy of Russia for the period until 2030. Approved by the decree of the Government of the Russian Federation №1715-r 13.11.2009 (updated 
version 01.01.2018)]. (In Russian). Available at: http://legalacts.ru/doc/rasporjazhenie-pravitelstva-rf-ot-13112009-n-1715-r/. (Accessed: 03.04.2018, In Russian).

19. Metallopolimernyye truby PRO AQUA PE-RT-AL-PE-RT. Pasport, tekhnicheskoye opisaniye i instruktsiya po ekspluatatsii [Metal-polymer pipes PRO AQUA PE-RTAL-PE-RT. Passport, datasheet and user manual]. Moskva: ProAkva ${ }^{\circledR}$ [Moscow: Pro$\mathrm{Akva}^{\circledR}$ ]. 2015. 5 p. Available at: http://docplayer.ru/43497720-Metallopolimernyetruby-pro-aqua-pert-al-pert.html. (accessed: 03.04.2018, In Russian).

20. SP 40-102-2000 Proyektirovaniye i montazh truboprovodov sistem vodosnabzheniya i kanalizatsii iz polimernykh materialov. Obshchiye trebovaniya. [SR 40-102-2000 Designing and installation of pipelines of water supply and sewage systems from polymeric materials. General requirements] Available at: http://dokipedia.ru/document/4675652. (Accessed: 03.04.2018, In Russian).

21. Kamershteyn A.G., Rozhdestvenskiy V.V., Ruchimskiy M.N. Raschety truboprovodov na prochnost'. Spravochnaya kniga. [Pipeline calculations for strength. Reference book]. Moscow: Gosudarstvennoye nauchno-tekhnicheskoye izdatel'stvo neftyanoy i gorno-toplivnoy literatury [Moscow: State scientific and technical publishing house of oil and mining-fuel literature]. 1963. $423 \mathrm{p}$. Available at: http://xn--90acg2babefdpm.xn--p1ai/static/books ～/2013/10/08/kamershtejn-raschet-magistralnyihtruboprovodov-na-prochnost-i-ustojchivost-1963.pdf. (Accessed: 03.04.2018, In Russian).

\section{DeAr Colleagues!}

THE REFERENCE TO THIS PAPER HAS THE FOLLOWING CITATION FORMAT:

Baikov I.R., Smorodova O.V., Kitaev S.V. Nanocomposite pipelines energy efficiency. Nanotehnologii v stroitel'stve = Nanotechnologies in Construction. 2018, Vol. 10, no. 3, pp. 20-36. DOI: dx.doi.org/10.15828/2075-8545-2018-10-3-2036. (In Russian). 


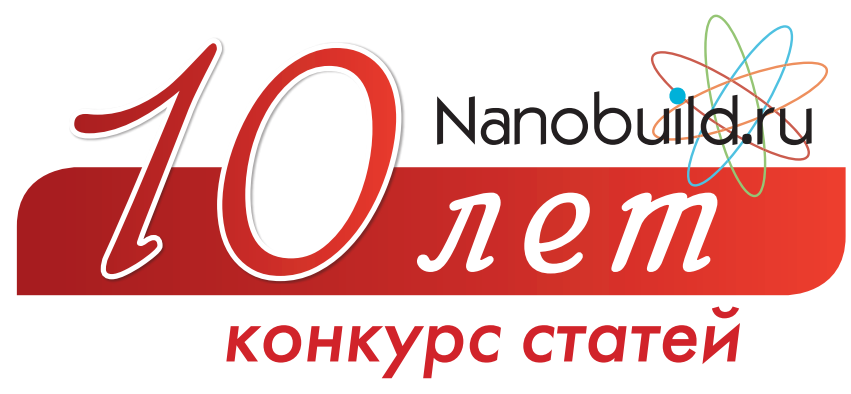

\section{УДК 621.186.2}

Автор: БАЙКОВ Игорь Равильевич, д-р техн. наук, проф., действительный член Академии горных наук, зав. каф. «Промышленная теплоэнергетика» ФГБОУ ВО «Уфимский государственный нефтяной технический университет»; ул.Космонавтов, д.1, г.Уфа, Республика Башкортостан, 450064, pte.ugntu@rusoil.net;

Автор: СМОРОДОВА Ольга Викторовна, канд. техн. наук, доц. каф. «Промышленная теплоэнергетика» ФГБОУ ВО «Уфимский государственный нефтяной технический университет»; ул. Космонавтов, д.1, г. Уфа, Республика Башкортостан, 450064, olga_smorodova@mail.ru; Автор: КИТАЕВ Сергей Владимирович, д-р техн. наук, действительный член Международной инженерной академии, проф. каф. «Транспорт и хранение нефти и газа», доц., ФГБОУ ВО «Уфимский государственный нефтяной технический университет»; ул. Космонавтов, д.1, г. Уфа, Республика Башкортостан, 450064, svkitaev@mail.ru

\section{ЭНЕРГЕТИЧЕСКАЯ ЭФФЕКТИВНОСТЬ НАНОКОМПОЗИТНЫХ ТРУБОПРОВОДОВ}

\section{АННОТАЦИЯ К СТАТЬЕ (АВТОРСКОЕ РЕЗЮМЕ, РЕФЕРАТ):}

В настоящее время все болышее распространение получают многослойные металлопластиковые трубы, изготовленные по специальным технологиям. Основные достоинства так называемых нанокомпозитных труб - повышенный срок эксплуатации (до 80-100 лет), прочность и неподверженность коррозии.

В статье рассмотрен энергетический аспект применения полимерных композитных труб. Показано, что благодаря низкой шероховатости даже на начальном этапе эксплуатации затраты электроэнергии на привод насосов в системе почти в 1,5 раза ниже аналогичного показателя систем со стальными трубопроводами. В перспективе из-за нарастания отложений в стальных трубопроводах эффект возрастает в среднем на 8\% за каждый последующий год эксплуатации.

Ключевые слова: нанотехнология, композитные трубы, шероховатость, потери напора, энергоэффективность. 
МАШИНОЧИТАЕМАЯ ИНФОРМАЦИЯ о CC-ЛИЦЕНЗИИ В МЕТАДАННЫХ СТАТЬИ (НTML-КОД):

$<$ a rel="license" href="http://creativecommons.org/licenses/by/4.0/"><img alt="Лицензия Creative Commons" style="borderwidth:0" src="https://i.creativecommons.org/l/by/4.0/88x31.png" / ></a $><$ br / Произведение «<span xmlns:dct="http:// purl.org/dc/terms/" href="http://purl.org/dc/dcmitype/Text" property="dct:title" rel="dct:type"> Энергетическая эффективность нанокомпозитных трубопроводов $</$ span > " созданное автором по имени <a xmlns:cc="http://creativecommons.org/ns\#" href="Нанотехнологии в строительстве. - 2018. -Toм 10, № 3. - С. 20-36. - DOI: dx.doi.org/10.15828/2075-8545-2018-10-320-36" property="cc:attributionName" rel="cc:attributionURL">Байков И.Р., Смородова О.В., Китаев С.В. </а>, публикуется на условия $<$ a rel="license" href="http://creativecommons.org/licenses/by/4.0/"> лицензии Creative Commons C указанием авторства 4.0 Всемирная $</ \mathrm{a}>$. $<$ br / $>$ Основано на произведении с $<$ a xmlns:dct="http://purl.org/dc/terms/" href="http:// nanobuild.ru/ru_RU/nanobuild-3-2018/" rel="dct:source">http://nanobuild.ru/ru_RU/nanobuild-3-2018/</a >.<br />Paзpeшения, выходящие за рамки данной лицензии, могут быть доступны на странице $<$ a xmlns:cc="http://creativecommons.org/ ns\#" href="pte.ugntu@rusoil.net"rel="cc:morePermissions">pte.ugntu@rusoil.net</a>.

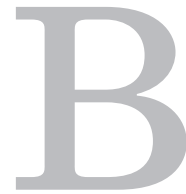

о второй половине прошлого столетия практически во всех странах мира наступил кризис надежности трубопроводных систем. Причиной негативных последствий продолжительной эксплуатации стальных инженерных коммуникаций явилась коррозия. Новые материалы для трубопроводного строительства - полимеры и медь - были лишены способности к коррозионному разрушению. Однако постепенно селитебное пространство мегаполисов наполнилось электромагнитными полями от многочисленной бытовой техники, что сформировало режим коррозионного разрушения и для медных инженерных коммуникаций. Таким образом, полимеры и их композиции стали единственной альтернативой металлическим трубопроводным системам.

Основные этапы создания современных трубопроводов на полимерной основе представлены на рис. 1.

После первоначально разработанных полимеров (полиэтилен низкого и высокого давления, полипропилен, полибутен) в 1972 году на рынке появился сшитый полиэтилен РЕХ. Но решающим шагом в создании труб нового поколения стала разработка металлопластиковых гибких труб PEX-AL-PEX - 5-слойной конструкции из сшитого полиэтилена PEX, алюминиевой фольги и клея [1]. Такая комбинация слоев позволила избавиться от основных недостатков полимерных труб (высокого коэффициента термического расширения) путем изменения их характеристик [2]. 


\begin{tabular}{|c|c|c|c|c|c|c|c|c|c|}
\hline 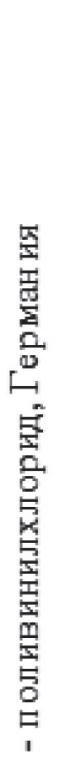 & 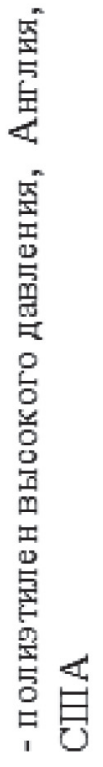 & 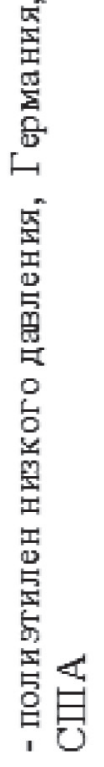 & 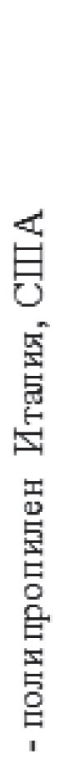 & 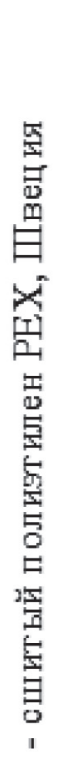 & 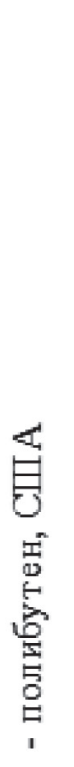 & 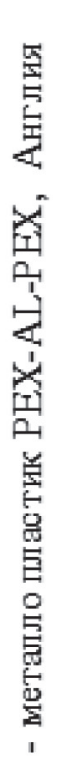 & 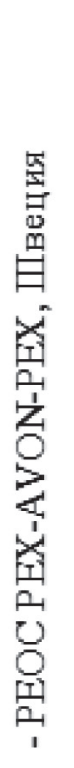 & 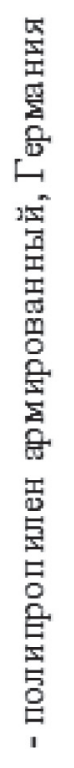 & 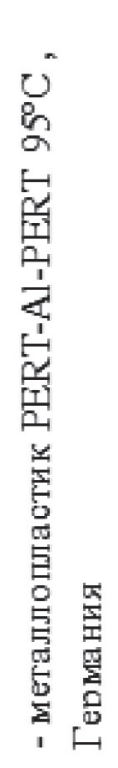 \\
\hline $\begin{array}{l}\stackrel{4}{2} \\
\stackrel{2}{\hookrightarrow}\end{array}$ & \begin{tabular}{c}
$\dot{8}$ \\
\multirow{2}{}{} \\
$\stackrel{\sigma}{\sigma}$
\end{tabular} & 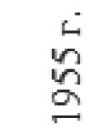 & $\begin{array}{l}\dot{\leftrightarrow} \\
\infty \\
\stackrel{\infty}{\sigma} \\
\stackrel{\sigma}{\sigma}\end{array}$ & $\stackrel{\dot{L}}{\mathcal{N}}$ & $\begin{array}{c}\dot{m} \\
\stackrel{2}{\Omega}\end{array}$ & $\begin{array}{l}\dot{5} \\
\alpha \\
\Omega\end{array}$ & $\begin{array}{l}\dot{L} \\
\stackrel{\Xi}{\sigma}\end{array}$ & $\begin{array}{c}\dot{L} \\
\stackrel{\Omega}{\Omega}\end{array}$ & $\stackrel{\dot{\Xi}}{\stackrel{\mathrm{S}}{\mathrm{S}}}$ \\
\hline
\end{tabular}

Рис. 1. Хронология разработки металлопластиковых трубопроводных материалов

Новый класс полиэтилена - PE-RT (Polyethylene of Raised Temperature) - был разработан (рис. 2a) для достижения повышенной термостойкости (до $\left.125^{\circ} \mathrm{C}\right)$ и гидростатической прочности (до $2,5 \mathrm{M \Pi а)} \mathrm{co} \mathrm{сро-}$ ком службы до 80 лет. Именно с использованием полиэтилена PE-RT производится в настоящее время почти $60 \%$ металлопластиковых труб мирового рынка (рис. 2б) [3, 4].

Для усиления длительной термостойкости и прочности труб разработаны нанокомпозитные составы [5]. Нанокомпозит представляет собой большое количество специальных нанослоев [6] с толщиной каждого из них не более $2 \times 10^{-9}$ м [7]. Изготавливается из глинистых минералов монтмориллонита [8]. Частицы монтмориллонита искусственно внедряются в полимер PE-RT [9] и образуют уникальный сверхпрочный материал.

Многослойная нанокомпозитная труба (рис. 3а) содержит как минимум один слой металлической фольги, по два слоя адгезивного материала [10] и полиэтилена PE-RT. Металлическая фольга, как правило, 


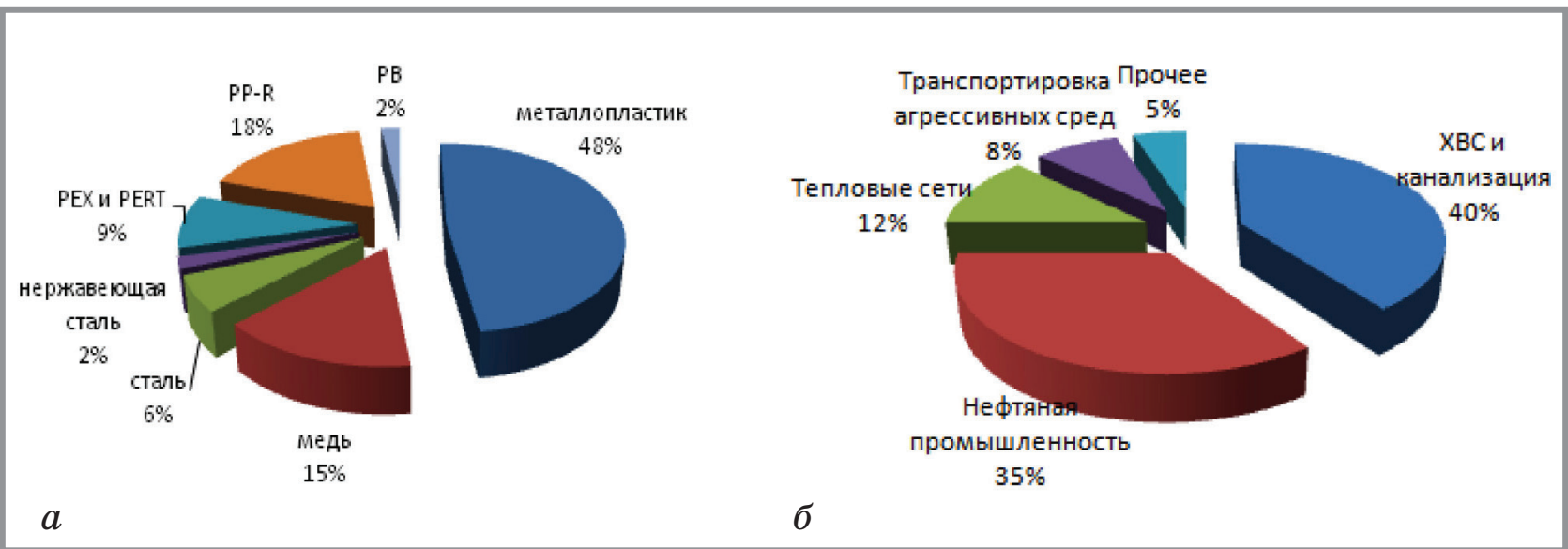

Рис. 2. Основные показатели современного рынка нанокомпозитных трубопроводов:

а - структура потребления труб, страны Евросоюза, 2015 г.;

б - сегменты сбыта композитных труб (по данным США)

выполнена из алюминия или углеродистой стали. Хотя бы на одной стороне поверхности фольги создан нанорельеф для увеличения сцепления между металлом и полимером PE-RT до значения не менее $150 \mathrm{H} / \mathrm{cm}$. Нанобугры (высота 50-100 нм и толщина основания 1 мкм) на поверхности фольги формируются воздействием плазмы высоковольтных барьерных разрядов атмосферного давления [11, 12, 13] (рис. 3б).

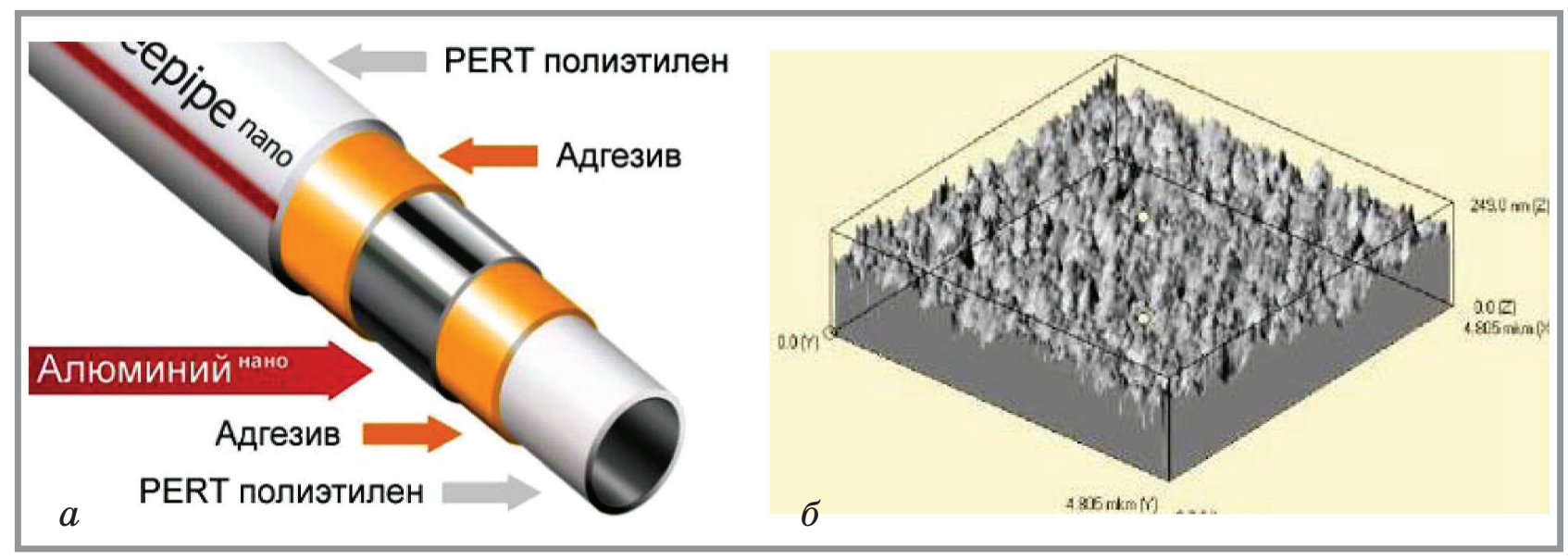

Рис. 3. Структура нанокомпозитной трубы:

a - конструкция нанокомпозитной трубы; б - результат воздействия барьерного разряда атмосферного давления на слой фольги 
Как результат создания многослойной конструкции [14] - повышение прочности $[15,16]$ соединений металл-полимер с увеличением механической прочности всей конструкции (до 6,7 МПа), термостойкости (до $150^{\circ} \mathrm{C}$ ), долговечности (до 100 лет) и снижением практически в 8 раз коэффициента ее температурного расширения с $20 \mathrm{Mm} /\left(\right.$ п.м. $\times 100^{\circ} \mathrm{C}$ ) (для полимеров) до 2,6 мм на п.м. при нагреве на каждые $100^{\circ} \mathrm{C}$. И главное преимущество нанокомпозитов - исключение разрушений водопроводных и газопроводных труб коррозией.

Однако не менее важным направлением в развитии технологий производства современных материалов для трубопроводного строительства является обеспечение высокой энергетической эффективности инженерных систем $[17,18]$. Напомним, что внутренний слой нанокомпозитной трубы, контактирующий с потоком (рис. 3а), выполнен из полиэтилена PE-RT. C точки зрения обеспечения оптимальных гидравлических режимов водяных трубопроводных сетей этот материал обладает следующими достоинствами:

- предельно низким долговечным значением шероховатости -

$0,0015 \mathrm{~mm}$;

- практически нулевой адгезионной способностью.

Для количественной оценки энергетического преимущества нанокомпозитных трубопроводов над стальными системами был выполнен расчет удельных потерь напора по длине трубопроводов и затрат электроэнергии на сетевом насосе для следующих условий:

- д диаметры трубопроводов сетей - от $\mathrm{DN}=50 \mathrm{~mm}$ до $\mathrm{DN}=400 \mathrm{~mm}$;

- температурные графики - от $95 / 70^{\circ} \mathrm{C}$ до $150 / 70^{\circ} \mathrm{C}$;

- $\quad$ средняя за отопительный период температура воздуха - $\left(-5,9^{\circ} \mathrm{C}\right)$.

Скорость сетевой воды была принята в соответствии с оптимальным гидравлическим режимом теплоносителя $-2 \mathrm{~m} / \mathrm{c}$. Вязкость сетевой воды задана в соответствии с температурными графиками источника по средним за отопительный период значениям температуры атмосферного воздуха восточноевропейской части России.

При сформулированных исходных данных были определены числа Рейнольдса в диапазоне от 162000 до 860000 для разных диаметров и температурных графиков сети, соответствующие турбулентной структуре потока. Для водяных стальных тепловых сетей при расчете коэффициента гидравлического сопротивления в этом случае рекомендуется формула Альтшуля: 


$$
\lambda=0,11 \times\left(\frac{\mathrm{k}_{\ni}}{\mathrm{d}}+\frac{68}{\mathrm{Re}}\right)^{0,25},
$$

где $\mathrm{k}_{э}$ - эквивалентная шероховатость, мм.

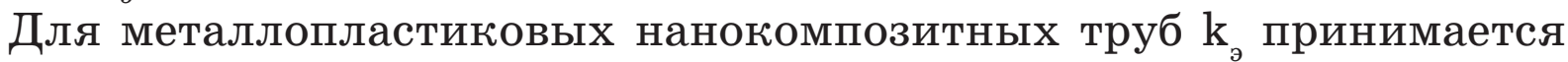
0,0015 мм [19]; для новых сварных стальных - 0,05 мм.

Расчет коэффициента гидравлического сопротивления нанокомпозитных трубопроводов выполнен в соответствии с рекомендациями нормативного свода правил [20]:

$$
\sqrt{\lambda}=\frac{0,5 \times\left[\frac{\mathrm{b}}{2}+\frac{1,312 \times(2-\mathrm{b}) \times \lg \left(3,7 \mathrm{~d} / \mathrm{k}_{\ni}\right)}{\lg \mathrm{Re}_{\phi}-1}\right]}{\lg \left(3,7 \mathrm{~d} / \mathrm{k}_{\ni}\right)},
$$

где b - критерий подобия режимов течения воды:

$$
\mathrm{b}=1+\frac{\lg \mathrm{Re}_{\phi}}{\lg \mathrm{Re}_{\text {кв }}}
$$

в случае получения значения $\mathrm{b}>2$ следует принимать $\mathrm{b}=2$;

$\mathrm{Re}_{\text {кв }}$ - критерий Рейнольдса, соответствующий нижней границе квадратичной области гидравлического сопротивления при турбулентной структуре потока воды, определяется по формуле

$$
\mathrm{Re}_{\text {кв }}=\frac{500 \mathrm{~d}}{\mathrm{k}_{\ni}} \text {. }
$$

При расчетах заданных режимов значение критерия $\mathrm{b}$ составило величины в диапазоне $1,6 \ldots 1,8$.

Результаты оценки коэффициентов гидравлического сопротивления стальных и нанокомпозитных труб показаны на рис. 4а. Расчеты показали, что расход электроэнергии на привод сетевого насоса при эксплуатации даже новых стальных трубопроводов превышает энергопотребление насоса нанокомпозитной системы на уровне $(17 . . .32) \%$ в зависимости от диаметра трубопровода. 


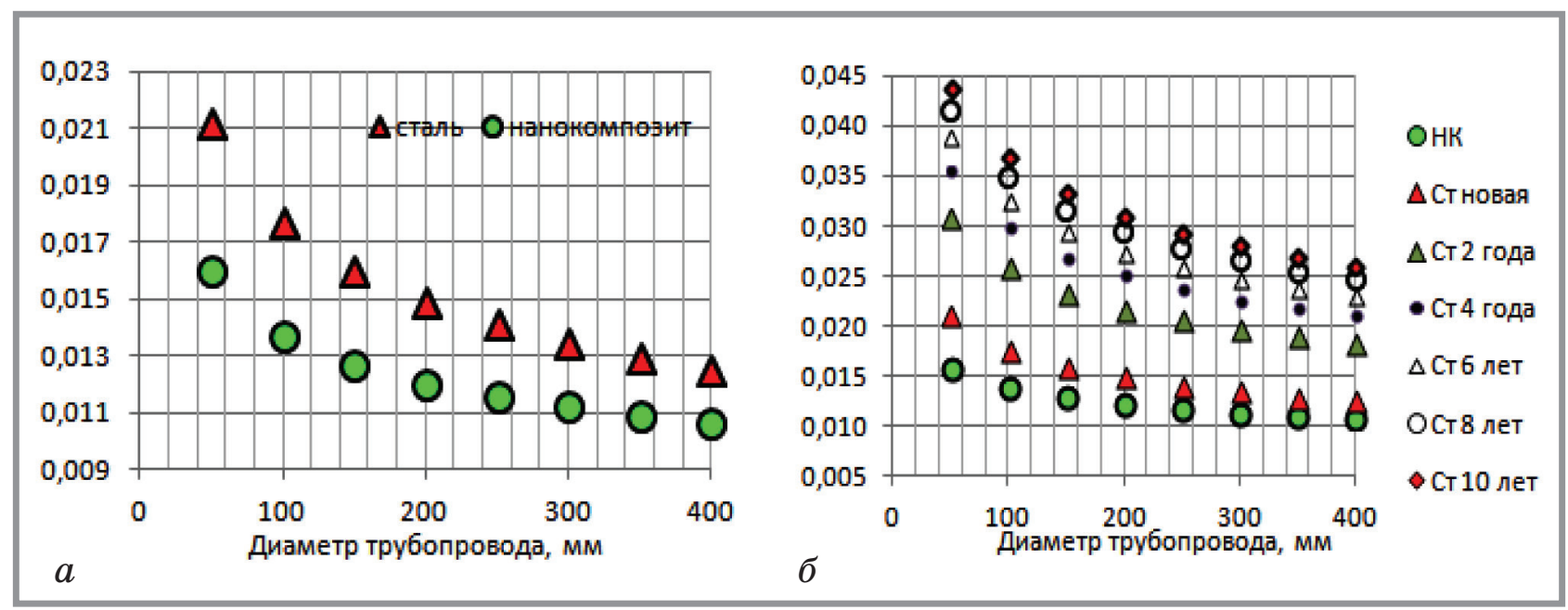

Рис. 4. Результаты сравнительного анализа гидравлической эффективности нанокомпозитных и стальных трубопроводов (температурный график $130 / 70^{\circ} \mathrm{C}$ ):

a - коэффициенты гидравлического сопротивления новых труб;

б - динамика коэффициентов гидравлического сопротивления в течение 10 лет

Существенно больший энергетический эффект от применения нанокомпозитных труб прогнозируется в перспективе (рис. 4б) - с течением времени эксплуатации в стальных трубопроводах образуются внутритрубные отложения, тогда как внутренняя поверхность нанокомпозитной трубы остается без изменения. Интенсивность нарастания отложений принята по Камерштейну А.Г. [21] для 2 группы пресных вод с умеренным коррозионным воздействием как минимум на уровне среднего рекомендуемого значения $0,12 \mathrm{mм} /$ год.

Результаты расчетов по годам с учетом нарастания отложений в стальных системах показали, что коэффициент относительного энергопотребления в стальных системах за 10 лет увеличится на $110 \%$, и в конце десятилетнего периода составит около 2,8 (рис. 5а).

С учетом идентификации максимального эффекта на малых диаметрах трубопроводов рекомендуется в первую очередь применять нанокомпозитные материалы для строительства внутриквартальных систем теплоснабжения.

Анализ целесообразности применения нанокомпозитных труб в зависимости от температурных графиков сети показал, что влияние температуры теплоносителя на относительную эффективность предложен- 


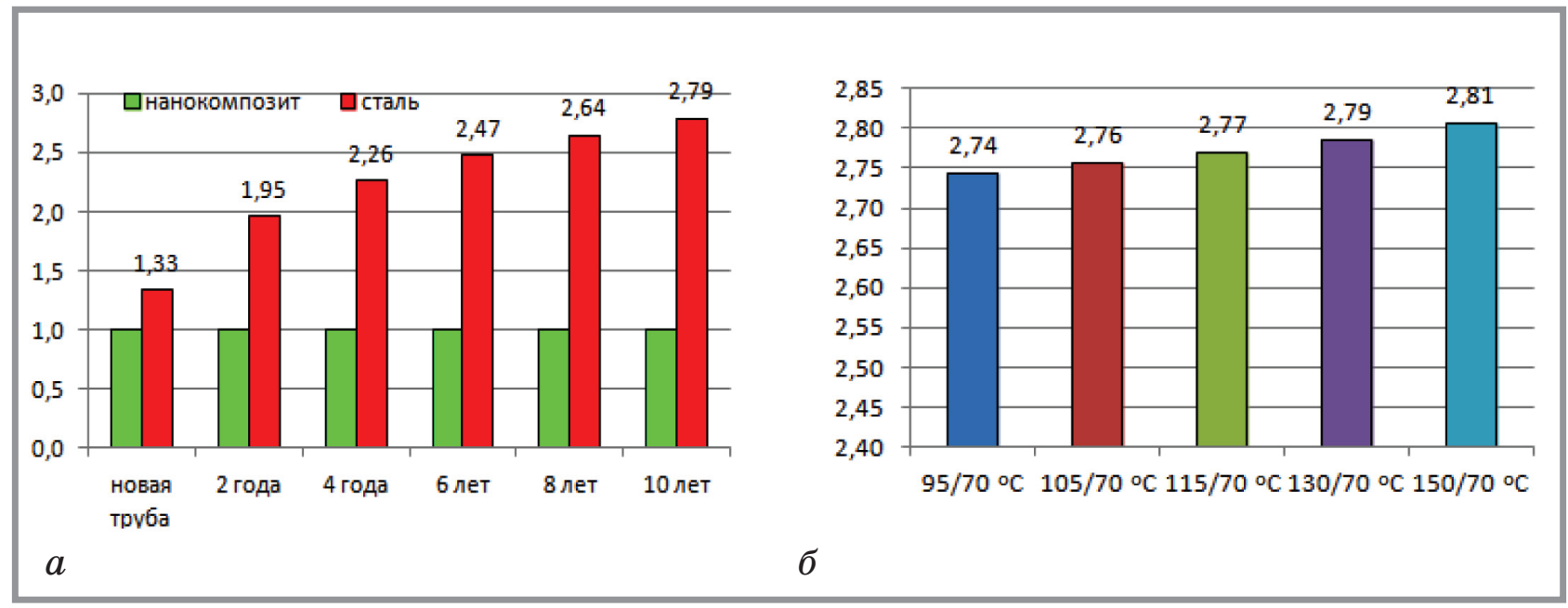

Рис. 5. Результаты оценки потребления электроэнергии насосом стальной системы теплоснабжения относительно нанокомпозитных систем:

a - относительное потребление ЭЭ с учетом образования внутритрубных отложений в стальных системах отопления, крат; б - относительное потребление ЭЭ с учетом температурных графиков систем теплоснабжения, крат

ного решения весьма не существенно (рис. 5б). Выбор нанокомпозитных труб для систем с температурным графиком $150 / 70^{\circ} \mathrm{C}$ по сравнению с $95 / 70^{\circ} \mathrm{C}$ обеспечит эффект в электроэнергии на привод сетевого насоса лишь на 2,2\% больше, что находится на уровне погрешности определения параметров эксплуатации системы.

Полный экономический эффект от применения нанокомпозитных трубопроводов был оценен по приведенным годовым затратам с учетом капитальных и эксплуатационных составляющих. В табл. 1 представлены сведения от производителя о стоимости предизолированных труб, стальных и нанокомпозитных.

Определение эффективности использования нанокомпозитных труб в системах теплоснабжения продемонстрировано на примере одной из нефтеперекачивающих станций системы магистрального транспорта нефти России с расчетной тепловой нагрузкой 1,85 Гкал/ч и температурным графиком $105 / 70^{\circ} \mathrm{C}$. Сетевой насос работает напором $14,6 \mathrm{M}$ и подачей $74 \mathrm{~m}^{3} /$ ч. Трубопроводная система площадки состоит из труб диаметром до 200 мм общей протяженностью 2574 м.

Результаты расчета годовых затрат на систему теплоснабжения приведены в табл. 2 и на рис. 6 . 
Таблица 1

Цены на предызолированные стальные и нанокомпозитные трубы

\begin{tabular}{|c|c|c|c|c|}
\hline \multirow{3}{*}{ № } & \multicolumn{2}{|c|}{$\begin{array}{c}\text { Предызолированная } \\
\text { стальная труба }\end{array}$} & \multicolumn{2}{|c|}{$\begin{array}{c}\text { Предызолированная } \\
\text { нанокомпозитная труба }\end{array}$} \\
\hline & $\begin{array}{c}\text { Наружный } \\
\text { диаметр } \\
\text { и толщина }\end{array}$ & Цена с НДС & $\begin{array}{c}\text { Внутренний } \\
\text { диаметр } \\
\text { и толщина }\end{array}$ & Цена с НДС \\
\hline & MM & руб/п.м. & MM & руб/п.м. \\
\hline 1 & $89 \times 4$ & 638 & $80 \times 3,0$ & 856 \\
\hline 2 & $108 \times 4$ & 800 & $100 \times 3,5$ & 1040 \\
\hline 3 & $133 \times 4$ & 1029 & $122 \times 3,5$ & 1317 \\
\hline 4 & $159 \times 4$ & 1312 & $150 \times 4,0$ & 1640 \\
\hline 5 & $219 \times 5$ & 2130 & $200 \times 4,5$ & 2490 \\
\hline 6 & $273 \times 6$ & 3529 & $250 \times 5,0$ & 3900 \\
\hline 7 & $325 \times 7$ & 4084 & $300 \times 5,5$ & 4050 \\
\hline 8 & $426 \times 8$ & 5865 & $400 \times 6,5$ & 5810 \\
\hline
\end{tabular}

Таблица 2

Приведенные годовые затраты в системе теплоснабжения

\begin{tabular}{|c|c|c|c|c|}
\hline № & $\begin{array}{c}\text { Наименование } \\
\text { показателя }\end{array}$ & Ед.изм. & $\begin{array}{c}\text { Стальные } \\
\text { предызолированные } \\
\text { трубопроводы }\end{array}$ & $\begin{array}{c}\text { Нанокомпозитные } \\
\text { предызолированные } \\
\text { трубопроводы }\end{array}$ \\
\hline 1 & $\begin{array}{l}\text { Срок службы } \\
\text { трубопроводов }\end{array}$ & лет & 15 & 70 \\
\hline 2 & $\begin{array}{l}\text { Полная стоимость } \\
\text { трубопроводов }\end{array}$ & тыс.р. & 1713 & 2178 \\
\hline 3 & $\begin{array}{l}\text { Приведенные годовые } \\
\text { капитальные затраты } \\
\text { на трубопроводы }\end{array}$ & $\begin{array}{l}\text { тыс.р. } \\
\text { в год }\end{array}$ & 114 & 31 \\
\hline 4 & $\begin{array}{l}\text { Электропотребление } \\
\text { сетевым насосом }\end{array}$ & $\begin{array}{c}\text { тыс.кВтч } \\
\text { в год }\end{array}$ & 29,111 & 14,555 \\
\hline 5 & $\begin{array}{l}\text { Затраты на } \\
\text { электроэнергию }\end{array}$ & $\begin{array}{c}\text { тыс.р. } \\
\text { в год }\end{array}$ & 87 & 44 \\
\hline 6 & $\begin{array}{l}\text { Суммарные годовые } \\
\text { затраты }\end{array}$ & $\begin{array}{l}\text { тыс.p. } \\
\text { в год }\end{array}$ & 201 & 75 \\
\hline
\end{tabular}




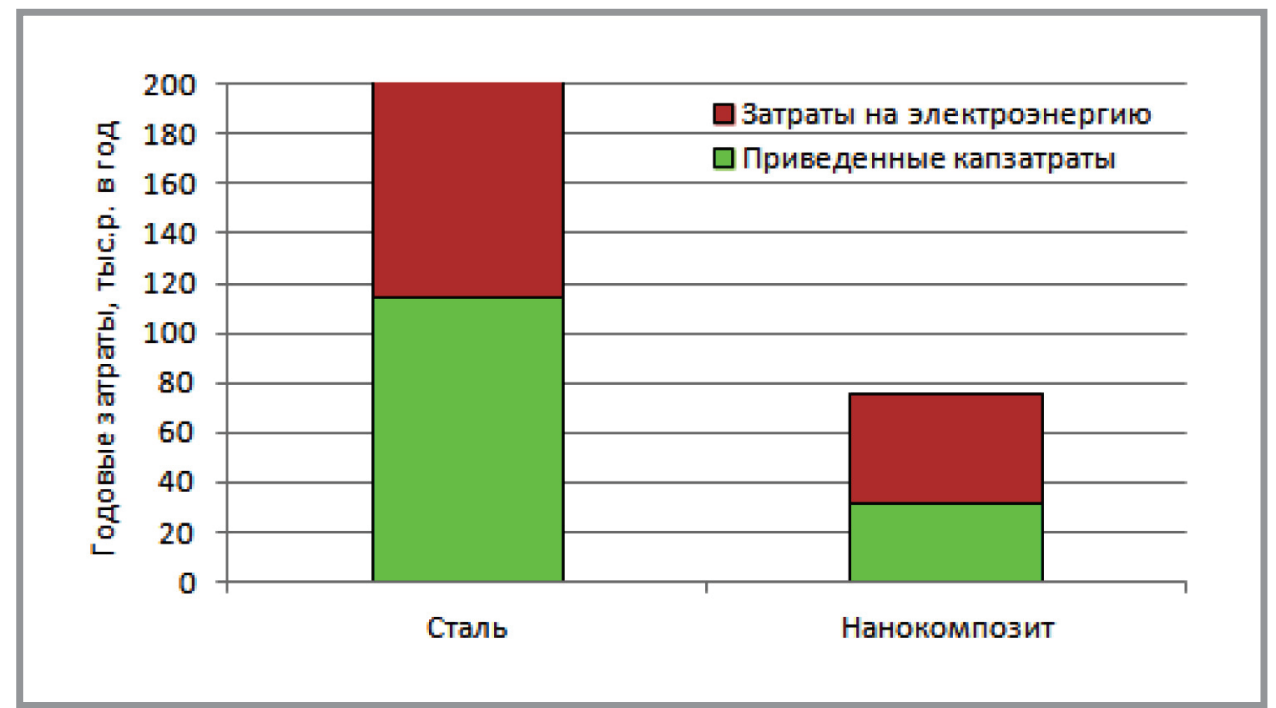

Рис. 6. Результаты оценки энергетической эффективности нанокомпозитных тепловых сетей

\section{Выводы:}

1. Положительный мировой и отечественный опыт использования полимерных композитных труб в отсутствии коррозионного разрушения и внутритрубных отложений прогнозирует благоприятные перспективы их применения, в особенности для внутриквартальных распределительных сетей систем теплоснабжения.

2. Показано, что кроме высоких показателей надежности нанокомпозитные трубопроводы гарантируют минимальные затраты электроэнергии на сетевом насосе. За 10 лет эксплуатации стальных трубопроводных коммуникаций годовое потребление электроэнергии на привод сетевого насоса станет в 2,8 раз больше, чем в системе с нанокомпозитными трубами.

3. Приведенные годовые капитальные затраты на строительство системы теплоснабжения с использованием нанокомпозитных трубопроводов более, чем в 3,5 раза, ниже аналогичного показателя стальных инженерных коммуникаций.

4. Учет совокупных годовых затрат на работу системы теплоснабжения обеспечивает нанокомпозитным трубопроводам по сравнению со стальными аналогами практически 3 -кратное экономическое преимущество. 


\section{Библиографический список:}

1. Поциус А.В. Клеи, адгезия, технология склеивания. - С-Петербург: «Профессия». - 2007. - С. 172-173.

2. Motuhari G. Thermoplastische ersetzen Stahl und Aluminium Текст. / G. Motuhari, F. Tabankia // Kunststoffe. 1999. № 3.pp. 74-76.

3. Gaube E. Kunststoffe im Rohrleitungs- und Apparatebau Tекст. / E. Gaube, G. Diedrich // Chemie Ingenieur Technik 1978. Vol. 50. № 3. pp. 155-166.

4. Meier K. Kunststoff-Rohre für Chemie-Anlagen Текст. / K. Meier // KunststoffRundschau. 1973. № 6. pp. 273-278.

5. Каримов Э.Х., Каримов О.Х., Мовсулзаде Э.М., Боев Е.В. Влияние наночастиц металла на механические характеристики композитных материалов // Нанотехнологии в строительстве: научный интернет-журнал. - 2017. - Т. 9, № 4. - С. 2247. - URL: https://elibrary.ru/download/elibrary_30031491_89739816.pdf (дата обращения: 03.04.2018).

6. Prodromou A.G., Lomov S.V., Verpoest I. The method of cells and the mechanical properties of textile composites // Composite Structures. 2011. Vol. 93. № 4. pp. 12901299.

7. Vallons K., Adolphs G., Lucas P., Lomov S.V., Verpoest I. The influence of the stitching pattern on the internal geometry, quasi-static and fatigue mechanical properties of glass fibre non-crimp fabric composites // Composites Part A: Applied Science and Manufacturing. 2014. Vol. 56. pp. 272-279.

8. Овчинников Н.Л., Арбузников В.В., Капинос А.П., Белозеров А.Г., Бутлан М.Ф. Влияние механоактивации монтмориллонита на эффективность интеркаляции полигидроксокомплексов алюминия при формировании слоисто-столбчатой структуры // Российские нанотехнологии. - 2015. - Т. 10, № 3-4. - С.74-79.

9. Бутлан М.Ф., Белозеров А.Г., Карасев Н.С., Кочкина Н.Е., Ходов И.А., Овчинни-

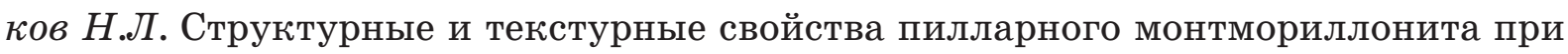

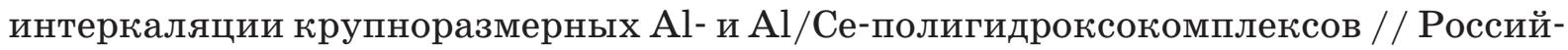
ские нанотехнологии. - 2015. - Т. 10, № 9-10. - С. 36-41.

10. Кудрявиев П.Г., Фиговский О.Л. Неорганические термостойкие связующие // Нанотехнологии в строительстве: научный интернет-журнал. - 2017. - Т. 9, № 6. C. 66-81. - URL: https://readera.ru/neorganicheskie-termostojkie-svjazujushhie-14265814. (дата обращения: 03.04.2018).

11. Ben Gardi R., Roth J.R. et al. Sterilization and plasma processing of room temperature surfaces with a one atmosphere uniform glow discharge plasma (OAUGDP) Surface Coatings Technology. 2000. P. 131. 
12. Carr A.K. Increase in the surface energy of metal and polymeric surfaces using the one atmosphere uniform glow discharge plasma MS in EE Thesis University of Tennesse. 1997.

13. Салойлович В.Г., Гибалов В.И., Козлов К.В. Физическая химия барьерного разряда. - M.: Издательство МГУ, 1989. - 176 с. - URL: http://www.studmed. $\mathrm{ru/samoylovich-vg-gibalov-vi-kozlov-kv-fizicheskaya-himiya-barernogo-}$ razryada_6154bef13ee.html\#. (дата обращения: 03.04.2018).

14. Каллыков А.В., Косников Г.А., Беспалов Э.Н., Петрович С.Ю. Композиты - алюминиевая матрица - тяжелые дисперсные частицы // Композиты и наноструктуpы. - 2017. - T. 9, № 3-4 (35-36). - C. 165-166. - URL: http://www.issp.ac.ru/ journal/composites/2017/Kalmykov-3-4-2017.pdf. (дата обращения: 03.04.2018).

15. Harris, B. Fatigue in composits Текст. / B. Harris. England: Woodheard Publish Lmt., 2003. $742 \mathrm{p}$.

16. Owen M.J. Failure of glass-reinforced plastics under single and repeated loading Текст. / M.J. Owen, R. Dukes // Journal of Strain Analysis for engineering design. 1967. Vol. 2. № 4. pp. 272-279.

17. Федеральный закон «Об энергосбережении и о повышении энергетической эффективности и о внесении изменений в отдельные законодательные акты Российской Федерации» от 23.11.2009 N 261-Ф3 (последняя редакция). - URL: http:// legalacts.ru/doc/FZ-ob-jenergosberezhenii-i-o-povyshen ossijskoj-Federacii/. (дата обращения: 03.04.2018).

18. Энергетическая стратегия России на период до 2030 года. Утверждена распоряжением правительства РФ №1715-р от 13.11.2009 (актуализированная версия от 01.01.2018). - URL: http://legalacts.ru/doc/rasporjazhenie-pravitelstva-rf-ot13112009-n-1715-r/. (дата обращения: 03.04.2018).

19. Металлополимерные трубы PRO AQUA PE-RT-AL-PE-RT. Паспорт, техническое описание и инструкция по эксплуатации / Москва: ПроАква ${ }^{\circledR}, 2015$. - 5 с. - URL: http://docplayer.ru/43497720-Metallopolimernye-truby-pro-aqua-pert-al-pert. html. (дата обращения: 03.04.2018).

20. СП 40-102-2000 Проектирование и монтаж трубопроводов систем водоснабжения и канализации из полимерных материалов. Общие требования. - URL: http:// dokipedia.ru/document/4675652. (дата обращения: 03.04.2018).

21. Калерштейн А.Г., Рождественский В.В., Ручилский М.Н. Расчеты трубопроводов на прочность. Справочная книга. - М.: Государственное научно-техническое издательство нефтяной и горно-топливной литературы. - 1963. - 423 c. - URL: http:// xn--90acg2babefdpm.xn--p1ai/static/books/2013/10/08/kamershtejn-raschetmagistralnyih-truboprovodov-na-prochnost-i-ustojchivost-1963.pdf. 
УВАЖАЕМЫЕ КОЛЛЕГИ!

ПРИ ИСПОЛЬЗОВАНИИ МАТЕРИАЛА ДАННОЙ СТАТЬИ

ПРОСИМ ДЕЛАТЬ БИБЛИОГРАФИЧЕСКУЮ ССЫЛКУ НА НЕЁ:

Байков И.Р., Слородова О.В., Китаев С.В. Энергетическая эффективность нанокомпозитных трубопроводов // Нанотехнологии в строительстве. - 2018. Toм 10, № 3. - C. 20-36. - DOI: dx.doi.org/10.15828/2075-8545-2018-10-3-20-36.

\section{DeAR COLlEAgues!}

THE REFERENCE TO THIS PAPER HAS THE FOLLOWING CITATION FORMAT:

Baikov I.R., Smorodova O.V., Kitaev S.V. Nanocomposite pipelines energy efficiency. Nanotehnologii $\mathrm{v}$ stroitel'stve $=$ Nanotechnologies in Construction. 2018, Vol. 10, no. 3, pp. 20-36. DOI: dx.doi.org/10.15828/2075-8545-2018-10-3-2036. (In Russian). 